\title{
Research on Driving Factors of Evolution of Antagonistic Conflicts Between Entrepreneurs and Investors Based on Grounded Theory
}

\author{
Hui Huo* Jiwei Sun \\ 1School of Management, Shanghai University, 20 Chengzhong Road, Shanghai 201800, China
}

\begin{abstract}
In this paper, 14 publicly reported actual cases reflecting antagonistic conflicts between entrepreneurs and investors are chosen, and a grounded theory approach is adopted to collect and analyze the original data of cases. Total of 108 concepts, 23 sub-categories, 6 main categories, and a core category of "driving factors of evolution of antagonistic conflicts" are obtained, and the model of driving factors of evolution of antagonistic conflicts between entrepreneurs and investors is constructed. This research shows that: (1) divergence of strategic objective, divergence of control right allocation, divergence of interests and moral hazard are the direct driving factors of antagonistic conflict evolution; (2) individual perceptions of both entrepreneurs and investors are the mediating driving factor of antagonistic conflict evolution; (3) antagonistic response is the situational driving factor of antagonistic conflict evolution. Finally, suggestions for preventing and resolving antagonistic conflicts between entrepreneurs and investors are provided according to the study.
\end{abstract}

Keywords: Antagonistic Conflict, Grounded Theory, Evolution of Conflict

DOI: $10.7176 / \mathrm{EJBM} / 11-14-01$

Publication date:May $31^{\text {st }} 2019$

\section{Introduction}

In recent years, the pioneering enterprises have been developed continuously. With the assistance of investors, including extending their financing channels, providing the support of funds and strategic resources, the pioneering enterprises can stand out in the background of fierce market competition. But then, as the study conducted by Yitshaki (2008) shows, the potential for conflicts between entrepreneurs and investors is great. With the rapid development of venture investment and equity investment, the number of cases reflecting conflicts between entrepreneurs and investors increased gradually. Among the various conflicts, the antagonistic conflict is the most intense one that usually results in negative consequences to investors, entrepreneurs and involved enterprise, such as one party being forced to quit, and the involved enterprise being closed down, and also has negative influences on the market environment of start-up and investment communities. However, most of the existing studies have focused on the various types of conflicts (Sun\& Zhang, 2014; Wu\& Zhou, 2012), or the phenomenon analysis and conclusion of a certain case (Sun \&Ruan, 2013), the study on evolution, prevention and resolving of antagonistic conflict is less. In this paper, the grounded theory is adopted and the publicly reported actual cases reflecting antagonistic conflicts between entrepreneurs and investors are collected to thoroughly analyze and explore the driving factors and evolution of antagonistic conflicts between entrepreneurs and investors, and provide countermeasures and suggestions for preventing and resolving antagonistic conflicts according to the study conclusions. This research is helpful for entrepreneurs and investors to learn how to prevent conflicts, and establish a good cooperative relationship.

\section{Theoretical Review}

\subsection{Concepts of antagonistic conflict}

As for the definition of conflict, in existing studies, a numerous scholars have explained it from various perspectives and based on their respective research fields. Early on, Coser (1956) defined it from the perspective of conflict generation as the process of scrambling for relevant status, value, rights and resources, and both subjects in conflict aim to do harm to benefits of the other, or even eliminate the other. Boulding (1963) defined the conflict as the divergence of two or more subjects arising from the disagreement on objectives, desires etc. Pinkley (1990) put forward in his study that conflict is the behavioral process of subjects in conflict from ideological conflict, to cognitive conflict, and to final decision. Thomas (1992) considered that the conflict usually experiences four stages, including frustration stage, conceptualization stage, behavior stage, and outcome stage, and it may recurrent or trigger new conflict if it cannot be handled properly. Additionally, based on the existing studies, Jr and Callister (2010) extended the scope of conflict process, and put forward that in the conflict process, one of the subjects in conflict will perceive that their interests being negatively affected or opposed by the other. Considering the definitions of conflict made from different perspectives, it can be concluded that the conflict is consisted by three essential factors: firstly, two or more subjects in conflict; secondly, the divergence between subjects in conflict; thirdly, the process of incurring relationship change or behavioral outcome by divergence. The antagonistic conflict 
is a form of conflict, which refers to the disagreement on important issues between related parties, and will evolve into or erupted into formal conflict. In this process, the subjects in conflict tend to take an uncompromising stance and will not make any mutual concession, or even give vigorous resistance.

\subsection{Development of conflict evolution theory}

Pondy (1967), one of the first scholars to study the conflict from the perspective of dynamic process, put forward the five-stage model of conflict evolution: potential conflict (conditions), perceived conflict (cognation), felt conflict (emotion), apparent conflict (behavior), and conflict aftermath (as shown in Figure 1).

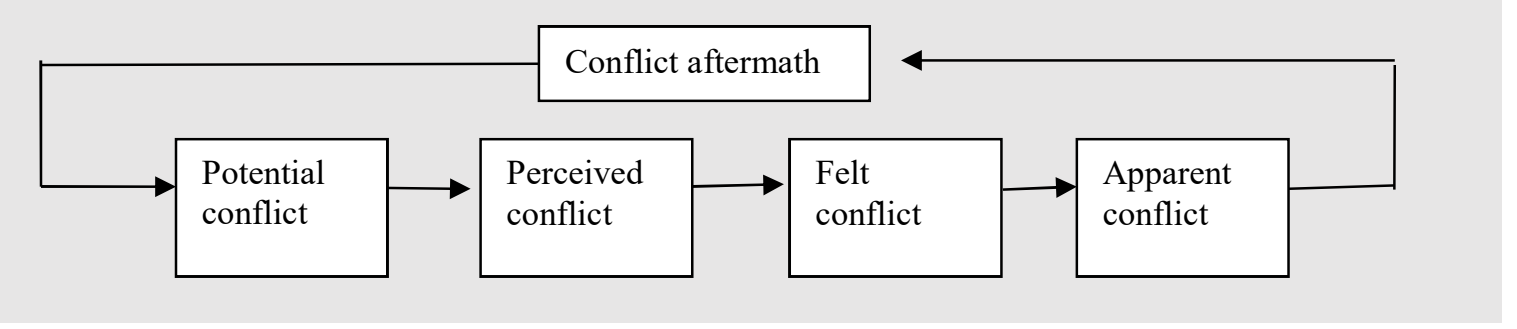

Figure 1. Pondy's five-stage model of conflict evolution

Hampton et al. (1968) considered that the extent of conflict mainly depends on: the degrees of goal incompatibility and source sharing between subjects in conflict. The lower the degree of goal incompatibility is, and the higher the degree of source sharing is, the lower the extent of conflict is; otherwise, the extent of conflict is higher. After that, Stephen P. Robbins (2001) put forward a more specific conflict evolution process than Pondy's five-stage model of conflict evolution, which is mainly consisted by five stages: potential opposition (or divergence), cognitive intervention, conflict intention, conflict behavior and consequence of conflict, as shown in Figure 2 .

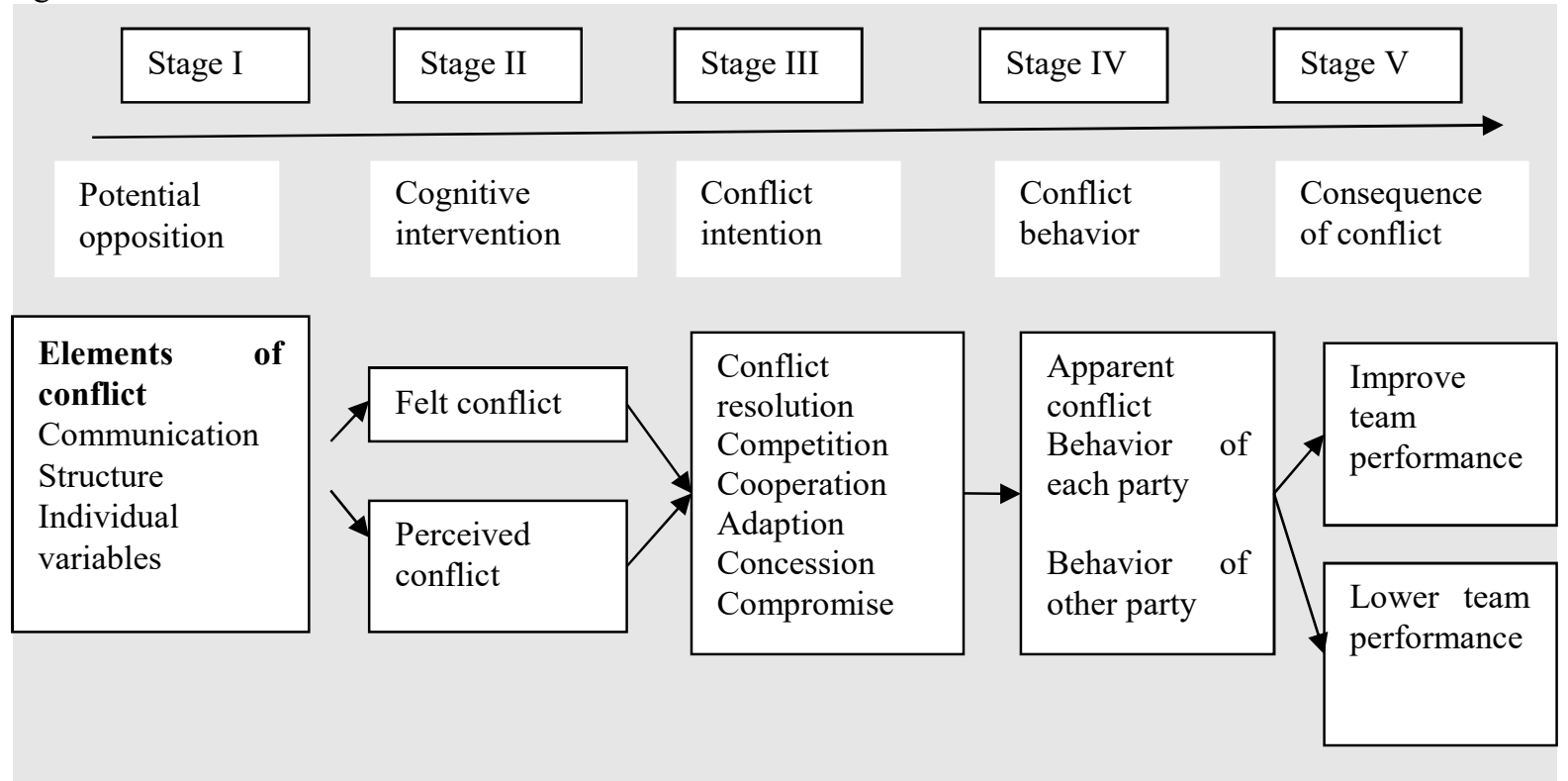

Figure 2. Robbins's five-stage model of conflict evolution

\section{Research design and methodology}

3.1 Methodology

The grounded theory, firstly put forward by Glaser (1978) and Strauss (2000), is defined as a qualitative research method in which the systematic procedure is adopted to develop and summarize relevant theories from a certain phenomenon, and has been widely adopted in enterprise management research and other related areas. The specific research processes of grounded theory include definition of phenomenon, literature survey, data collection and analysis, 3-level coding (open coding, axial coding, and selective coding), construction of preliminary theory, and theoretical saturation etc. (Edlinger, 2015). In this paper, according to this idea, the open coding will be firstly conducted to analyze original data one by one and label them with relevant concepts, and then classify and combine the data with similar concepts to get the concepts of higher level, i.e. categories, thus to realize the conceptualization and categorization of data. After that, the axial coding will be conducted to summarize and get the main categories. Finally, the second-level codes will be summarized and refined in the process of selective coding to get core category of evolution of antagonistic conflict between entrepreneurs and investors. 


\subsection{Case selection}

The selected cases in this paper revolve around the research topic of "evolution of agonistic conflicts between entrepreneurs and investors". These cases also meet the following case collection criteria: firstly, the involved enterprises have disclosed the conflict events between entrepreneurs and investors, and provided so much comprehensive event information that sufficient for research; secondly, the conflicts between entrepreneurs and investors are antagonistic conflicts, and the final consequences of conflicts were obtained after the evolution process of conflict.

\section{Construction of evolution model of antagonistic conflicts between entrepreneurs and investors \\ 4.1 Open coding}

Open coding refers to the process of disorganizing and splitting raw data, giving new concepts and re-associating the data by new methods (Stol, Ralph \& Fitzgerald, 2016). In the process of open coding, the coder is required to abandon personal bias and research definition prejudice, and restore all data to its original appearance for coding with open mind (Stol, Ralph \& Fitzgerald, 2016). In this cycle, the original data and research questions will be reduced through definition of phenomenon, development of concept and refine of categories etc. In this paper, the coding analysis software NVIVO8 was used for open coding of collected raw data. After repeated summary and analysis, total of 108 original statements (expressed by the serial number of "X-a+", where X refers to the case number, "a+" refers to the serial number of the statement in this case) and corresponding primary concepts (expressed by the serial number of "aa+") were obtained. After that, the concepts were summarized into some more abstract categories, and total of 19 categories (expressed by the serial number of "A+") were obtained. The 19 categories are operation principle, income distribution, trust level, communication level, goal of listing, realization of performance, containment of power, restructuring, commercial ethics, education background, personality characteristics, openness of conflict, embezzlement, influence of management, physical abuse, decision-making, capital operation, consciousness of law and discipline, and organization structure.

\subsection{Axial coding}

In the process of axial coding, based on the classical pattern of causal conditions $\rightarrow$ phenomenon $\rightarrow$ context $\rightarrow$ intervening conditions $\rightarrow$ action-interaction $\rightarrow$ consequence, 19 categories obtained in the process of open coding were connected and refined into 6 main categories: divergence of strategic objective, divergence of control right allocation, divergence of interests, moral hazard, antagonistic response, individual perceptions. At the same time, the chain of evidence validating the classical mode of each main category was formed. Taking the divergence of strategic objective as example, the casual condition is goal of listing, the phenomenon is divergence of strategic objective, the context includes capital operation and hopeless in listing, the intervening conditions are operational principle and decision-making, the action interaction includes censure and intervention, and the result is strategic goal dominated antagonistic conflict.

Table 1. Main categories formed in the process of axial coding

\begin{tabular}{|c|c|c|}
\hline Main categories & Sub-categories & Connotation of category \\
\hline \multirow{3}{*}{$\begin{array}{l}\text { Divergence of } \\
\text { strategic objective }\end{array}$} & $\begin{array}{l}\text { Operation principle } \\
\text { (A1) }\end{array}$ & $\begin{array}{l}\text { Development ideas, future planning, product orientation and the } \\
\text { like of involved enterprise }\end{array}$ \\
\hline & Goal of listing (A5) & $\begin{array}{l}\text { Whether the involved enterprise will be listed, the listing time and } \\
\text { location, and other events revolve around listing }\end{array}$ \\
\hline & $\begin{array}{l}\text { Organization } \\
\text { structure (A19) }\end{array}$ & $\begin{array}{l}\text { Department setup, function planning etc. within the involved } \\
\text { enterprise }\end{array}$ \\
\hline \multirow{2}{*}{$\begin{array}{l}\text { Divergence of } \\
\text { control right } \\
\text { allocation }\end{array}$} & $\begin{array}{l}\text { Influence of } \\
\text { management (A14) }\end{array}$ & Actual speaking right and influence of each party in management \\
\hline & $\begin{array}{l}\text { Decision-making } \\
\text { and operation (A16) }\end{array}$ & $\begin{array}{l}\text { Strategies or operation procedure adopted for realization of certain } \\
\text { goal of involved enterprise }\end{array}$ \\
\hline \multirow{3}{*}{$\begin{array}{l}\text { Divergence of } \\
\text { interests }\end{array}$} & $\begin{array}{l}\text { Income distribution } \\
\text { (A2) }\end{array}$ & $\begin{array}{l}\text { Including salary structure, reward mechanism, benefit allocation } \\
\text { method etc. }\end{array}$ \\
\hline & $\begin{array}{l}\text { Realization of } \\
\text { performance(A6) }\end{array}$ & $\begin{array}{l}\text { Whether the performance objectives of involved enterprise have } \\
\text { reached the promises between both parties }\end{array}$ \\
\hline & $\begin{array}{l}\text { Capital operation } \\
\text { (A17) }\end{array}$ & $\begin{array}{l}\text { As the fund providers of involved enterprises, investors usually } \\
\text { seek to maximum of interest return }\end{array}$ \\
\hline \multirow[b]{2}{*}{ Moral hazard } & $\begin{array}{l}\text { Commercial ethics } \\
\text { (A9) }\end{array}$ & $\begin{array}{l}\text { In the cooperative process, one party does not abide by the contract } \\
\text { commitments, violates the stipulations or cheat the other party }\end{array}$ \\
\hline & $\begin{array}{l}\text { Consciousness of } \\
\text { laws and } \\
\text { disciplines(A18) }\end{array}$ & $\begin{array}{l}\text { In order to realize their respective objectives, one party does not } \\
\text { abide by stipulations, and acts against the laws and disciplines }\end{array}$ \\
\hline
\end{tabular}




\begin{tabular}{|c|c|c|}
\hline Main categories & Sub-categories & Connotation of category \\
\hline \multirow{5}{*}{$\begin{array}{l}\text { Antagonistic } \\
\text { response }\end{array}$} & $\begin{array}{l}\text { Containment of } \\
\text { power(A7) }\end{array}$ & $\begin{array}{l}\text { One party take further control of the involved enterprise, to contain } \\
\text { the rights of other party }\end{array}$ \\
\hline & $\begin{array}{l}\text { Openness of } \\
\text { conflict(A12) }\end{array}$ & $\begin{array}{l}\text { One party disclose the conflict through internal meeting or } \\
\text { external media }\end{array}$ \\
\hline & Embezzlement(A13) & $\begin{array}{l}\text { When the conflict occurs, one party take further actions harming } \\
\text { the interests of other party, such as assets transfer, related } \\
\text { transaction etc. }\end{array}$ \\
\hline & Physical abuse(A15) & One party takes such violence acts as physical confrontation \\
\hline & Restructuring(A8) & $\begin{array}{l}\text { Including turnover of personnel, structural adjustment, equity } \\
\text { adjustment }\end{array}$ \\
\hline \multirow{4}{*}{$\begin{array}{l}\text { Individual } \\
\text { perceptions }\end{array}$} & Trust level(A3) & $\begin{array}{l}\text { The degree of trust in morality and ability of one party to other } \\
\text { party }\end{array}$ \\
\hline & $\begin{array}{l}\text { Communication } \\
\text { level (A4) }\end{array}$ & $\begin{array}{l}\text { Communication channels, willing and efficacies of both parties in } \\
\text { the process of cooperation }\end{array}$ \\
\hline & $\begin{array}{l}\text { Personality } \\
\text { characteristics } \\
\text { (A11) }\end{array}$ & Their own features or differences in terms of disposition \\
\hline & $\begin{array}{l}\text { Education } \\
\text { background (A10) }\end{array}$ & $\begin{array}{l}\text { Cognitive learning abilities of both parties in relevant industry or } \\
\text { personal skills. }\end{array}$ \\
\hline
\end{tabular}

\subsection{Selective coding}

Selective coding refers to the process of developing a core category from main categories (Stol, Ralph \& Fitzgerald, 2016). In this process, the connections between these categories were explored repeatedly to improve the level of abstraction of these concepts, thus to develop the core category that can systematically cover some categories, and include related variables into a simple and compact theoretical framework in the form of "story line". Finally, the model of driving factors of evolution of antagonistic conflicts between entrepreneurs and investors was constructed (see Figure 3).

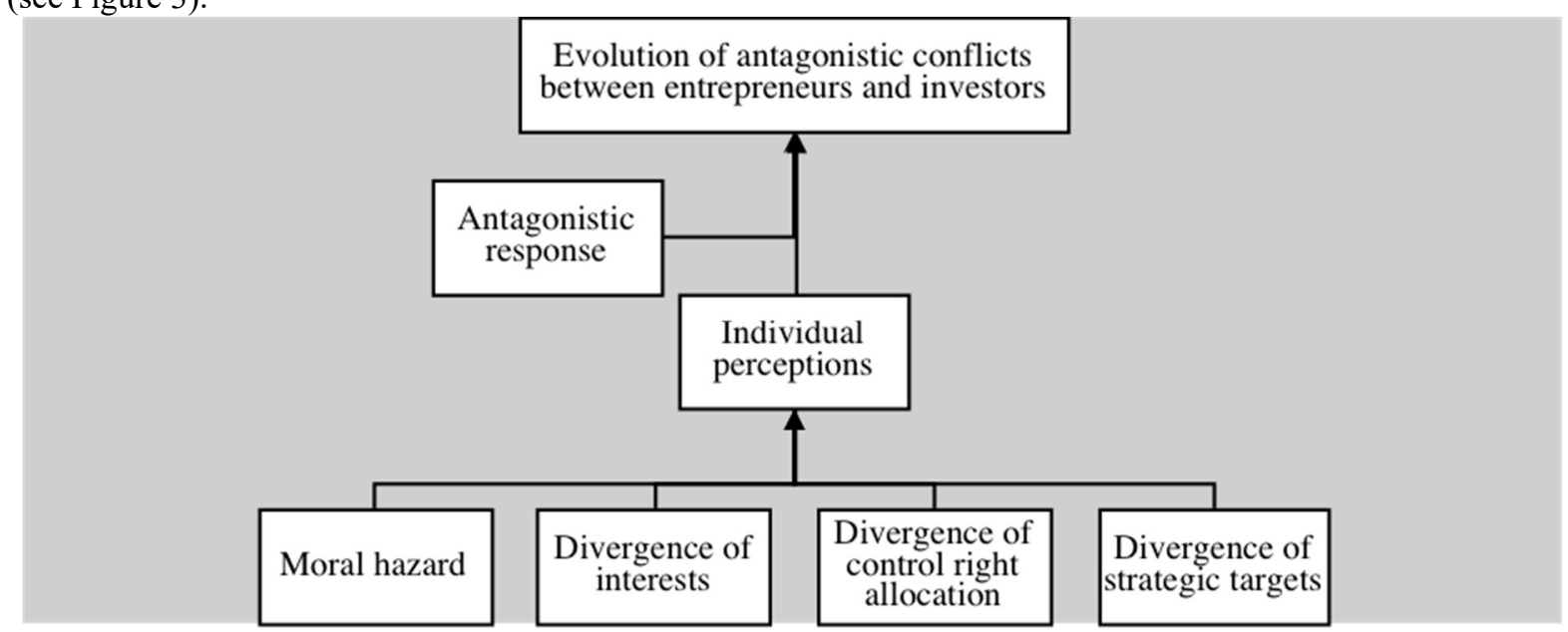

Figure 3. Model of driving factors of evolution of antagonistic conflicts between entrepreneurs and investors

\subsection{Test of theoretical saturation}

Theoretical saturation refers to the moment that no additional characteristic of a category or no additional category can be refined by collecting additional data (Stol, Ralph \& Fitzgerald, 2016). In this paper, additional five published reports about antagonistic conflicts between entrepreneurs and investors were chosen for data collection and analysis. The results showed that no additional category or structural relationship was found, and they are all consistent with the evolution model of antagonistic conflict between entrepreneurs and investors. Therefore, the category coding and factor model have passed the test of theoretical saturation.

\section{Model analysis on evolution of antagonistic conflicts between entrepreneurs and investors}

5.1 Direct driving factors of evolution of antagonistic conflicts between entrepreneurs and investors

The direct driving factors of evolution of antagonistic conflicts between entrepreneurs and investors, i.e. the sources of antagonistic conflicts, can be classified into four categories: divergence of strategic objective, divergence of control right allocation, divergence of interests, and moral hazard. 


\subsubsection{The divergence of strategic objective}

The divergence of strategic objective between entrepreneurs and investors mainly manifests in organization structure, operational principle, and goal of listing. The time length of divergence of strategic objective will result in difference in antagonistic conflict perception between both parties, and as a result, one party will take antagonistic measures firstly, and the other party will take similar actions later, which will finally result in breakdown of their cooperative relationship.

5.1.2 The divergence of interests

The divergence of interests between entrepreneurs and investors mainly manifests in income distribution, realization of performance, capital operation. The degree of divergence will affect the individual perception of antagonistic conflict, which will result in antagonistic conflict, and finally, breakdown of their cooperative relationship. For example, in case the performance of involved enterprise fails to reach the promises of both parties or the expectation of one party, one party might be discontent with the other party, which will result in occurrence or further evolution of antagonistic conflict. In case the capital operation fails due to the passive cooperation of one party, the other party's perception of antagonistic conflict will become intensive, which will promote the evolution of antagonistic conflict.

5.1.3 The divergence of control right allocation

The divergence of control right allocation between entrepreneurs and investors mainly manifests in influence of management and decision-making\& operation. The party with more control right usually has greater influence and more speaking right in the enterprise, and therefore have prime influence on degree of antagonistic conflict. The party with less control right will have strong perception of antagonistic conflict and will take strong antagonistic response, which will promote the evolution of antagonistic conflict between both parties.

5.1.4 The divergence of moral hazard

The divergence of moral hazard mainly manifests in commercial ethics and consciousness of laws and disciplines. In case one party violates the commercial ethics frequently, the other party will have strong perception of antagonistic conflict, and is more likely to take antagonistic countermeasures (Collewaert \& Fassin, 2013). When one party breaks laws and disciplines (such as operating illegally to obtain individual interests, regardless of the commitments between both parties), and results in the breakdown of their relationship (the common phenomena include related transaction, benefit transfer, capital embezzlement etc.), the other party is more willing to take antagonistic countermeasures.

\subsection{Situational driving factors of evolution of antagonistic conflicts between entrepreneurs and investors}

The antagonistic response has a regulating effect in antagonistic conflict evolution, and the degree of antagonistic response has a decisive influence on the conflict consequences in primary evolution stage. The antagonistic response includes physical abuse, openness of conflict, embezzlement, containment of power, and restructuring.

In case either entrepreneur or investor takes physical abuse firstly, their willing of keeping antagonism will be enhanced, which will finally promote the evolution of antagonistic conflict between both parties, and result in breakdown of their relationship.

In case one party takes the strategy of disclosing antagonistic conflict, the attentions of stakeholders of enterprises or social media will be drawn. The public opinion and internal negative response are conductive to moderating further evolution of antagonistic conflict between the two parties.

The fact that one party takes such countermeasures as embezzlement, containment of power and restructuring will lead to the appearance of antagonistic conflict and intensifying of antagonistic conflict, which might finally result in fracture of their relationship. Generally, antagonistic response is not a simple behavior, but a serial of complex behaviors appeared successively, which will promote the evolution of antagonistic conflict between both parties.

\subsection{Mediating driving factor of evolution of antagonistic conflicts between entrepreneurs and investors}

The mediating driving factor of evolution of antagonistic conflict between entrepreneurs and investors is individual perception, which depends on the communication level, trust level, personality characteristics, education background and other factors of parties in the conflict. When the level of communication between entrepreneur and investor is low, the perception of and response to antagonistic conflict of one party will be enhanced, this will promote the evolution of antagonistic conflict between both parties. Similarly, when the trust level of both parties is low, the perception of and response to antagonistic conflict of both parties will be enhanced, which will promote the evolution of antagonistic conflict.

\section{Summary and Suggestions}

6.1 Conclusions

In this research, 14 typical cases reflecting antagonistic conflicts between entrepreneurs and investors were collected, and a grounded theory approach was utilized to analyze these cases through a whole process including 
open coding, axial coding and selective coding. In the process of open coding, after removing the concepts that do not meet the criteria, total of 108 concepts and 19 sub-categories were obtained. In the process of axial processing, the data was further summarized and refined to get 6 main categories. In the process of selective coding, a core category that can systematically cover the categories, i.e. "driving factors of evolution of antagonistic conflicts", was obtained through higher level of conceptual abstraction, and the model of driving factors of evolution of antagonistic conflicts between entrepreneurs and investors was constructed. The divergence of strategic objective, divergence of control right allocation, divergence of interests and moral hazard are the direct driving factors of antagonistic conflict evolution. Individual perception is the mediating driving factor of antagonistic conflict evolution that can mediate the relation strength between direct driving factors and antagonistic conflict. The antagonistic response is the situational driving factor of antagonistic conflict evolution.

\subsection{Suggestions}

In real life, antagonistic conflicts do harm to involved enterprise, entrepreneurs and investors. Therefore, based on the conclusions mentioned above, some suggestions for preventing and resolving antagonistic conflicts are provided:

6.2.1 Suggestions for preventing antagonistic conflicts between entrepreneurs and investors

I. In prior to the formal investment, both parties shall initiate investigations on each other's background to get knowledge of the core team, investment philosophy, and operation \&management philosophy, thus to determine whether their work styles match each other and are conductive to cooperation and multi benefits, and then sign the cooperative agreement (Sun \& Li, 2018). In the current equity investment market, the investors often have a comprehensive investigation on entrepreneurs and their main businesses, products, teams as far as possible before investment. However, the entrepreneurs rarely have investigation on the investors' style, strength and preference. Therefore, in order to find more suited investors, entrepreneurs shall have comprehensive investigations on and understanding of background of investors, thus to avoid antagonistic conflicts occurring in the later cooperation process.

II. After signing the investment cooperation agreement, both parties shall abide by the rules, respect each other, have all-round cooperation, improve the communication and trust level, and make an agreement on strategic objectives and major decisions of the enterprise through friendly negotiation. In fact, after capital investment, many investors only pay attention to the financial related data, rather than other resources required by the involved enterprise, which might reduce the trust between the entrepreneurs and investors. Therefore, in the process of cooperation, entrepreneurs shall improve the consciousness of resource integration, while investors shall establish a correct investment concept. Both parties shall strive to enhance mutual trust and cooperation, make an agreement on objectives, thus to achieve cooperation and multi benefits.

6.2.2 Suggestions for resolving antagonistic conflicts between entrepreneurs and investors

I. Due to the differences in role, personality, and interest between entrepreneurs and investors, they might have divergence or even conflict in some aspect in the process of cooperation. As a large number of real cases show, failure in resolving antagonistic conflicts will often result in such negative business results as liquidation, bankruptcy, and suspension to the involved enterprise, and losses to both parties. Therefore, when the conflict occurs, both parties shall keep the overall interest in mind and reach a conflict resolution friendly, thus to achieve common goals and long-term interests.

II. One party may bring the conflict to an impartial third party for mediation in a timely manner, thus to prevent further deterioration of antagonistic relation that will result in both losses. When an antagonistic conflict occurs, the entrepreneur and investor are in the emotional antagonism stage, it is difficult for them to communicate rationally and reach an agreement with each other, and they are even likely to take aggressive behaviors. At this time, if one party can promptly bring it to a third parties with impartiality and prestige (such as government agencies) for mediation, it is possible for both parties to have friendly negotiation to resolve the conflict.

\section{References}

Boulding, K. E. (1963). Conflict and defense: a general theory. Western Political Quarterly, 15(4), 736.

Coser, L. (1956). The functions of social conflict. American Sociological Review, 22(1), 112.

Collewaert, V. , \& Fassin, Y. . (2013). Conflicts between entrepreneurs and investors: the impact of perceived unethical behavior. Small Business Economics, 40(3), 635-649.

Edlinger, \& Gabriela. (2015). Employer brand management as boundary-work: a grounded theory analysis of employer brand managers" narrative accounts. Human Resource Management Journal, 25(4), 443-457.

Glaser, B. G. (1978) Theoretical Sensitivity: Advances in the Methodology of Grounded Theory. Mill Valley: Sociology Press.

Pinkley, R. L. (1990). Dimensions of conflict frame: disputant interpretations of conflict. Journal of Applied Psychology, 75(2), 117-126.

Pondy, L. R. (1967). Organizational conflict: concepts and models. Administrative Science Quarterly, 12(2), 296- 
320.

Yitshaki, R. . (2008). Venture capitalist-entrepreneur conflicts: an exploratory study of determinants and possible resolutions. International Journal of Conflict Management, 19(3), 262-292.

Robbins, S. P. (2001). Organizational Behavior, 17/E. Organizational behavior. Ninth Edition. Prentice Hall.

Strauss, A., \& Corbin, J. (2000). Basics of qualitative research: techniques and procedures for developing grounded theory, 2nd edn, reviewed by nic beech. Management Learning.

Sun J. W. \& Ruan J. K. (2013) The Conflicts between Entrepreneurs and Investors and Its Countermeasures: A Multi-case Study. Chinese Journal of Management, 10(09):1275-1282.

Sun J. W. \& Zhang A. L. (2014) War and Peace between Entrepreneurs and Investors. PKU Business Review, 10:98-105.

Sun J. W. \& Li X. L. (2018) Research on the Driving Factors of Entrepreneur out Based on the Theory of Conflict between Entrepreneurs and Investors. Chinese Journal of Management, 5(15):718-725.

Stol, K. J. , Ralph, P. , \& Fitzgerald, B. . (2016). Grounded Theory in Software Engineering Research: A Critical Review and Guidelines. 38th International Conference on Software Engineering. IEEE.

Thomas, K. W. (1992). Conflict and negotiation processes in organizations. Md Dunnette \& Lm Hough Handbook of Industrial \& Organizational Psychology, Palo Alto, Ca: Consulting Psychologists.

Jr, J. A. W., \& Callister, R. R. (2010). Conflict and its management. Clinical \& Experimental Dermatology, 7(5), 557-564.

Wu, J. J. \& Zhou, Q. (2012) Stage Conflict Types of Venture Capital and its Managing Strategies. ScienceTechnology and Management, 14(1):74-77. 